\title{
Importância da avaliação no desempenho escolar
}

Isaac da Costa Silva*

RESUMO

O presente estudo versa sobre "A importância da avaliação no desempenho escolar", com o intento de conhecer a notabilidade desta prática de trabalho no processo de ensino e aprendizagem. Esta análise bibliográfica foi amparada em autores diversos que contribuíram com declaração acerca dos aspectos que desenvolve e tornam coerente com esta sistematização. A avaliação é um instrumento valioso e indispensável no sistema escolar, podendo descrever os conhecimentos, atitudes ou aptidões que os alunos apropriaram. Sendo assim a avaliação revela os objetivos de ensino já atingidos num determinado ponto de percurso e também as dificuldades no processo de ensino aprendizagem, sendo assim um grande desafio para o docente e toda a comunidade escolar. Este estudo contou com contribuições de autores como Kraemer (2006), Luckesi (2001), Mendez (2002) Haydt (1988), Sant'anna (1998) e outros.

Palavra-chave: Avaliação. Ensino-aprendizagem e conhecimentos

* FICS - Facultad Interamericana de Ciencias Sociales; Mestrando em Ciências da Educação. Asunción - PY. Contatos: Email: isaak28@hotmail.com (77) 999698460 


\section{INTRODUÇÃO}

Avaliação é um substantivo feminino que significa ato de avaliar, pode ser também sinônimo de estimativa ou apreciação.

No âmbito da pedagogia a avaliação escolar é um processo sistematizado de registro e apreciação dos resultados obtidos em relação metas educativas estabelecidas previamente.

A avaliação de aprendizagem é mais frequente no caso dos alunos, e é feita através de provas escritas, orais, testes, participação nas aulas, etc., a aquisição de conhecimentos e de habilidades para a adaptação bem-sucedida em um mundo submetido a constantes transformações.

Assim, para serem aprendizes efetivos por toda a vida, os jovens precisam de base sólida em domínios chave e devem ser capazes de organizar e gerir o aprendizado, o que requer consciência a respeito da própria capacidade de raciocínio e de estratégias e métodos de aprendizado.

O objetivo deste estudo é compreender os diversos tipos de avaliações e suas variações.

No presente estudo serão descritas algumas considerações sobre a importância da avaliação no processo educacional. Em seguida os autores trazem esclarecimentos sobre a importância da avaliação, avaliação diagnostica, avaliação formativa e avaliação somativa para o processo avaliativo. 


\section{Importância da avaliação no desempenho escolar}

Para Kraemer (2006), avaliação vem do latim, e significa valor ou mérito ao objeto em pesquisa, junção do ato de avaliar ao de medir os conhecimentos adquiridos pelo indivíduo. É um instrumento valioso e indispensável no sistema escolar, podendo descrever os conhecimentos, atitudes ou aptidões que os alunos apropriaram. Sendo assim a avaliação revela os objetivos de ensino já atingidos num determinado ponto de percurso e também as dificuldades no processo de ensino aprendizagem.

Esses casos atestam a possibilidade efetiva de desenvolvimento de pesquisas de vários tipos, até da mais rigorosa pesquisa acadêmica, mesmo nas nossas escolas. É verdade que elas não representam a situação comum das escolas da rede pública no país, como já ficou dito. Mas, guardadas as devidas distâncias, creio que podemos, a partir de seu estudo, discutir um pouco o estado atual da questão do professorpesquisador e seu saber, tal como vem sendo apresentada por alguns dos seus estudiosos. (LUCKESI, 2001, p.14)

Percebe-se que o ato de avaliar é amplo e não se restringe ao único objetivo, vai além da medida, posicionando-se favorável ou desfavorável à ação avaliada, propiciando uma tomada de decisão.

Sob a ótica de Sant'Anna (1998) avaliação é:

um processo pelo qual se procura identificar, aferir, investigar e analisar as modificações do comportamento e rendimento do aluno, do educador, do sistema, confirmando se a construção do conhecimento se processou, seja este teórico (mental) ou prático. (SANT'ANNA, 1998, p.29-30)

A concepção de avaliação dos PCNs - Parâmetros Curriculares Nacionais (1997) vai além da visão tradicional, que focaliza o controle externo do aluno mediante notas ou conceitos, para ser compreendida como parte integrante e intrínseca ao processo educacional.

A avaliação, não se restringe ao julgamento sobre sucessos ou fracassos do aluno, é compreendida como um conjunto de atuações que tem a função de alimentar, sustentar e orientar a intervenção pedagógica. Acontece contínua e sistematicamente por meio da interpretação qualitativa do conhecimento construído pelo aluno.

Segundo os Pcns (1997), avaliar significa 
"emitir em juízo de valor sobre a realidade que se questiona, seja proposito das exigências de uma ação que se projetou realizar sobre ela, seja a propósito de suas consequências". (PCNS, 1997, p. 86)

Sabemos que a avaliação não acontece de qualquer maneira num vazio conceitual, mas enfocada por um modelo de mundo e de educação que visa o alcance de resultados cada vez mais aceitável. O verdadeiro papel da avaliação é o de auxiliar na construção da aprendizagem pela superação do antidemocrático, no estabelecimento da autonomia do educando, na transformação da sociedade a favor do ser humano.

Somente assumindo o papel de diagnóstica, a avalição se constituirá num momento retórico no processo de aprendizagem do aluno, para que isso realmente ocorra, é necessário que o educador planeje sua prática pedagógica, compreendendo o estágio em que cada um dos seus alunos se encontram, para que possa trabalhar com eles, fazendo - os avançar no que se refere aos conhecimentos necessários.

A respeito de uma aprendizagem significativa, os Pcn's (1997) colocam que é

necessária à disponibilidade para o envolvimento do aluno na aprendizagem, o empenho em estabelecer relações entre o que já sabe e o que está aprendendo. Essa aprendizagem exige uma ousadia para se colocar problemas, buscar soluções, e experimentar novos caminhos, de maneira diferente da aprendizagem mecânica, no qual o aluno limita seu esforço apenas em memorizar ou estabelecer relações diretas e superficiais. (PCNs, 1997, p.99)

A citação acima abre o entendimento possibilitando uma reflexão sobre o papel do professor no processo de ensino - aprendizagem, buscando uma conciliação entre o que o aluno já sabe e o que ele está aprendendo.

A realidade da maioria das escolas da sociedade brasileira se torna um trabalho complicado, pois, encontra alunos com disparidades de conhecimentos, com realidades diferentes e professores com dificuldades de compreensão para atender as demandas da sala de aula.

Luckesi (2003) nos alerta sobre o perigo de continuar exercendo o mesmo tipo de avaliação que era exercida nas décadas passadas, que levava em consideração a promoção em vez da verdadeira aprendizagem.

Pais, sistema de ensino, profissionais da educação, professores e alunos, todos têm suas atenções centradas na promoção, ou não, do estudante de uma série de escolaridade para outra. O sistema de ensino está 
interessado nos percentuais de aprovação/reprovação do total dos educandos; os pais estão desejosos de que seus filhos avancem nas séries de escolaridade; os professores se utilizam permanentemente dos procedimentos de avaliação como elementos motivadores dos estudantes, por meio da ameaça; os estudantes estão sempre na expectativa de virem a ser aprovados ou reprovados e, para isso, servem-se dos mais variados expedientes. O nosso exercício pedagógico escolar e atravessado mais por uma pedagogia do exame que por uma pedagogia do ensino/aprendizagem. (LUCKESI, 2003, p. 18)

De alguma maneira, sempre atrelamos os resultados às notas, necessárias no processo avaliativo, uma vez que os educadores não dispõem de concepção e tempo para fazerem uma avaliação mais precisa, através de meios mais eficazes e de observações e, além de uma série de fatores que prejudicam a avaliação diagnóstica, como as salas de aulas lotadas e alunos com diferenças alarmantes de nível de aprendizagem.

Dentro dos objetivos da educação, e principalmente na perspectiva de inclusão social, não há como deixar de refletir sobre a atual avaliação predominante nas escolas, uma vez que ela é fundamental no processo de ensino-aprendizagem e na tomada de decisões, com o objetivo de melhorar a qualidade do ensino e da aprendizagem. Exatamente o que é expresso no Art. $9^{\circ}$, Inciso VI da LDB 9394/96 sobre as incumbências da União:

Assegurar o processo nacional de avaliação do rendimento escolar no ensino fundamental, médio e superior, em colaboração com os sistemas de ensino, objetivando a definição de prioridades e a melhoria da qualidade de ensino. (BRASIL, 2002, p. 10).

O papel da avaliação, como mediadora do processo de ensino-aprendizagem dos alunos, possibilita uma reflexão embasada nos dados obtidos por meio desse processo. Caso o professor perceba que sua prática não está favorecendo a todos, ele poderá refletir e adaptar uma prática mais acessível e igualitária.

De acordo com Luckesi (2003), a avaliação que se pratica na escola é a avaliação da culpa. Aponta, ainda, que as notas são usadas para fundamentar necessidades de classificação de alunos, onde são comparados desempenhos e não objetivos que se deseja atingir.

A função social da escola é atender todos os indivíduos da maneira mais eficaz, portanto os seus conteúdos devem ser flexíveis e significativos. Estes conteúdos devem auxiliar os jovens que planejam ir para a cidade, fazer um vestibular, cursar uma faculdade, adquirir um emprego. 
Mas devem auxiliar igualmente aqueles que por algum motivo justo desejam permanecer residindo nos lugares áridos e íngremes, onde nasceram seus pais e precisam produzir com qualidade o seu milho, feijão, batata, alface e viver com dignidade tendo acesso ao rádio, a televisão, ao telefone, aos mesmos bens tecnológicos que qualquer outro.

\section{Tipos de Avaliação}

De acordo com Sant'Anna (2013) avaliação é o processo pelo qual se comprovam as modificações do comportamento e rendimento tanto do educando, quanto do professor e do sistema, buscando confirmar se a construção do conhecimento de fato se processou.

Enfatiza ainda que avaliação da aprendizagem, como processo de conscientização da ação educativa, adquiriu diferentes funções de acordo com o contexto histórico, o modelo de sociedade e o tipo de educação adotada, razão pela qual compreende a forma como vem sendo concebido o ato de avaliar incorporado ao sistema educacional brasileiro faz-se necessário uma viagem histórica.

Nessa perspectiva Luckesi (2003) enfatiza que a

A tradição dos exames escolares, que conhecemos hoje, em nossas escolas, foi sistematizada nos séculos XVI e XVII, com as configurações da atividade pedagógica produzidas pelos padres jesuítas (séc. XVI) e pelo Bispo John Amós Comênio (fim do séc. XVI e primeira metade do século XVII). (Luckesi, 2003, p. 16)

Todas as atividades avaliativas, queiram ou não, servem para medir o grau de desenvolvimento intelectual, social e moral dos alunos. O objetivo do processo de ensino e da educação é que todas as crianças desenvolvam suas capacidades físicas e intelectuais, seu pensamento independente e criativo, tendo em vista atividades teóricas e práticas.

Para Méndez

(...) a avaliação torna-se importante no momento da informação prática aos professores sobre a qualidade das aprendizagens que os alunos estão realizando. Ao mesmo tempo, oferece uma boa oportunidade para melhorar tanto o processo de aprendizagem (...) quanto às ações futuras de ensino mediante a reflexão, a autocrítica e a autocorreção a partir da prática escolar. (MÉNDEZ, 2002, p. 74)

A avaliação deve favorecer o desenvolvimento de todas as crianças, levando-se em conta que todas são diferentes, tanto no nível socioeconômico, como nas características 
individuais. A avaliação possibilita o autoconhecimento de cada um, da sua posição em relação à classe, estabelecendo uma base para atividades de ensino-aprendizagem. Avaliar não se restringe somente a fazer provas e aplicar trabalhos.

Desde o momento que entra na sala de aula, o professor já faz uma avaliação ao olhar para os alunos, avalia a roupa que eles estão vestindo, o tipo que está o cabelo, a forma que se comunica com os colegas, etc. Também ao conversar com o aluno, o professor o avalia, nos seus gestos, na sua maneira de se comportar e pensar.

A avaliação não acontece em um só momento, ela acontece o tempo todo. Como ressalta Quintana (2003, p. 163), “[...] temos que ver a avaliação como um aspecto integral do processo de ensino-aprendizagem e como parte essencial das tarefas que o docente executa em aula".

Podemos classificar a Avaliação como sendo de três tipos: a diagnóstica, a formativa e a somativa. A seguir descrevemos cada uma delas.

\subsection{Avaliação Diagnóstica}

A avaliação diagnóstica é aquela que acontece geralmente no começo do ano letivo, antes do planejamento, onde o professor verifica os conhecimentos prévios dos alunos, o que eles sabem e o que não sabem sobre os conteúdos, não tem a finalidade de atribuir nota.

De acordo com Jorba e Sanmartí (2003), a avaliação diagnóstica, também chamada de avaliação inicial, “[...] tem como principal objetivo determinar a situação de cada aluno antes de iniciar um determinado processo de ensino-aprendizagem, para poder adaptá-lo a suas necessidades". (Jorba e Sanmartí, 2003, p. 27)

Para Luckesi (2000, p. 09), “[...] para avaliar, o primeiro ato básico é o de diagnosticar, que implica, como seu primeiro passo, coletar dados relevantes, que configurem o estado de aprendizagem do educando ou dos educandos".

Dessa forma:

A avaliação diagnóstica é aquela realizada no início de um curso, período letivo ou unidade de ensino, com a intenção de constatar se os alunos apresentam ou não o domínio dos pré-requisitos necessários, isto é, se possuem os conhecimentos e habilidades imprescindíveis para as novas aprendizagens. É também utilizada para caracterizar eventuais problemas de aprendizagem e identificar suas possíveis causas, numa tentativa de saná-los. (HAYDT, 1988, p. 16-17) 
A avaliação diagnóstica permite a captação de progressos e dificuldades do aluno, visando através dos mesmos, uma modificação no processo de ensino que possibilite concretizar seus objetivos. Ela permite o alcance de propósitos como: verificar se o aluno estabelece ou não determinados conhecimentos ou habilidades que são necessários para aprender algo novo, identificar, discriminar, compreender, caracterizar as causas determinantes das dificuldades de aprendizagem, ou essas próprias dificuldades.

Nessa ótica Sant'anna (1998) diz que:

O diagnóstico se constitui por uma sondagem, projeção e retrospecção da situação de desenvolvimento do aluno, dando-lhe elementos para verificar o que aprendeu e como aprendeu. É uma etapa do processo educacional que tem por objetivo verificar em que medidas os conhecimentos anteriores ocorreram e o que se faz necessário planejar para selecionar as dificuldades encontradas. (SANT'ANNA, 1998, p.33)

É muito importante a realização de um diagnóstico no início do ano letivo, fazendo com que o professor receba dados sobre o nível de conhecimento do aluno, e através destes o professor poderá planejar melhor sua prática, priorizando os conteúdos mais deficitários.

Esse tipo de avaliação funciona como um diagnóstico da realidade que se pretende examinar, fornecendo uma informação prévia acerca dos aspectos enfocados.

Machado (1995, p. 33) observa que

“A avaliação diagnóstica possibilita ao educador e educando detectarem, ao longo do processo de aprendizagem, suas falhas, desvios, suas dificuldades, a tempo de redirecionarem os meios, os recursos, as estratégias e procedimentos na direção desejada". (MACHADO, 1995, p. 33)

A avaliação diagnóstica também tem a função de ajustar os conhecimentos dos educandos em relação aos programas de ensino, ou vice-versa. O professor pode detectar que está ensinando com base num programa muito fácil para o nível de determinados alunos e alterar o programa ou, da mesma forma, perceber as dificuldades dos estudantes em relação a um programa e ajudá-los a compreender melhor o que está sendo ensinado. (HADJI, 2001, p. 19)

Um médico não se preocupa em classificar seus pacientes, dos menos doentes até os terminais. Tampouco destina a eles o mesmo tratamento. Ao contrário, dedica-se a encontrar para cada doente o tratamento 
adequado e, por isso, utiliza-se do diagnóstico para conhecer cada um deles. Porém, o diagnóstico sozinho não tem utilidade alguma. É verdadeiramente inútil se depois dele não vier uma ação apropriada. Com a avaliação também é assim: o diagnóstico é importante, mas de nada adianta se a ele não se sucederem ações concretas. (PERRENOUD, 2008, p. 15)

É importante observar e saber que não é o diagnóstico em si que faz a diferença (embora ele seja muito importante), para se analisar o grau de conhecimento de cada estudante, mas sim a ação que se desenvolve depois de formulado o diagnóstico para direcionar o trabalho de forma eficiente e organizada para ter a qualidade no processo de ensino e aprendizagem.

$\mathrm{Na}$ visão de Haydt, um dos propósitos da avaliação com função diagnóstica é "informar o professor sobre o nível de conhecimento e habilidades de seus alunos, antes de iniciar o processo ensinoaprendizagem, para determinar o quanto progrediram depois de um certo tempo". (Haydt, 1988, p. 20)

Diante disso:

Uma avaliação diagnóstica ou inicial faz um prognóstico sobre as capacidades de um determinado aluno em relação a um novo conteúdo a ser abordado. Trata-se de identificar algumas características de um aluno, objetivando escolher algumas sequencias de trabalho mais bem adaptadas a tais características. Tenta-se identificar um perfil dos sujeitos, antes de iniciar qualquer trabalho de ensino, sem o que, com certeza, estaria comprometido todo o trabalho futuro do professor. $\mathrm{O}$ diagnóstico é o momento de situar aptidões iniciais, necessidades, interesses de um indivíduo, de verificar pré-requisitos. É antes de tudo, momento de detectar dificuldades dos alunos para que o professor possa melhor conceber estratégias de ação para solucioná-las. (RABELO, 1998, p. 72)

Ao iniciar o período letivo, é recomendado que o professor faça uma avaliação diagnóstica da sua classe, para verificar o que os alunos aprenderam nos anos anteriores, quais os conhecimentos prévios que eles estão levando para aquela série. Sabemos que é frequente o nível de conhecimento variar de aluno para aluno de uma mesma série, por ser alunos de culturas diferentes, capacidade maior de assimilação do que lhe é proposto.

Por meio da avaliação diagnóstica, o professor analisa os conhecimentos já alcançados pelos alunos, suas experiências pessoais, seus raciocínios e estratégias espontâneas, suas atitudes adquiridas em relação à aprendizagem, para em seguida adequar seu conteúdo às 
necessidades e dificuldades dos alunos e para que estes se conscientizem de seu ponto de partida.

Segundo Luckesi (2002, p. 82), “[...] se o conhecimento ou habilidade é importante e o aluno não o adquiriu, há que trabalhar para que adquira [...]”.

Dessa forma:

A avaliação diagnóstica servirá de ajuda ao processo de ensino aprendizagem: fornecerá aos professores elementos que permitem identificar os conhecimentos prévios dos alunos, bem como os pontos críticos para que se avance na construção do conhecimento, tendo em vista um projeto de escola não-excludente. (CANEN, 1999, p. 15-16)

Na análise de avaliação diagnóstica é necessário um diálogo constante entre os que serão os avaliadores e os avaliados, para alavancar a construção do conhecimento e o crescimento intelectual de alunos e professores.

Para isso, diversos instrumentos podem ser utilizados nesse tipo de avaliação, de acordo com a criatividade dos professores e os recursos disponíveis em sua realidade, tais como: provas, testes, portfólio, questionários, roteiros de observação e de entrevista com alunos e pais de alunos.

De acordo com Luckesi (2003), para que a avaliação diagnóstica seja possível, é preciso compreendê-la e realizá-la comprometida com uma concepção pedagógica. No caso, considerarmos que ela deva estar comprometida com uma proposta pedagógica históricocrítica, uma vez que esta concepção está preocupada com a perspectiva de que o educando deverá apropriar-se criticamente de conhecimentos e habilidades necessárias à sua realização como sujeito crítico dentro desta sociedade que se caracteriza pelo modo capitalista de produção.

A avaliação diagnostica não se propõe e nem existe uma forma solta isolada. É condição de sua existência e articulação com uma concepção pedagógica progressista. (Luckesi 2003, p.82)

Mas o que se observa que a grande maioria dos professores utiliza apenas como meio de avaliação as provas escritas e testes surpresas como um meio de acerto de contas para aqueles alunos que deram trabalhos durante o semestre letivo.

\subsection{Avaliação Formativa}


Segundo Haydt (1998) a avaliação formativa, exerce a função de controle e é realizada durante todo o decorrer do período letivo, com o intuito de verificar se os alunos estão atingindo os objetivos previstos, isto é, quais os resultados alcançados durante o desenvolvimento das atividades. [...]. É principalmente através da avaliação formativa que o aluno conhece seus erros e acertos e encontra estimulo para um estudo sistemático. (HAYDT, 1988, p. 17-18)

Essa modalidade de avalição busca identificar as principais insuficiências de aprendizagens iniciais necessárias à realização de outras aprendizagens. Nesse sentido, é formativa no instante em que indica como os alunos estão se comportando em relação aos objetivos propostos.

A avaliação formativa buscaria, além disso, compreender o funcionamento cognitivo do aluno em face da tarefa proposta. Os dados de interesse prioritário são os que dizem respeitos as representações das tarefas explicitadas pelo aluno e as estratégias ou processos que ele utiliza para chegar a certos resultados. Os "erros" constituem objeto de estudo particular, visto que são reveladores da natureza das representações ou das estratégias elaboradas por ele. A finalidade da recuperação pedagógica será ajudar o aluno a descobrir aspectos pertinentes da tarefa e comprometer-se na construção de uma estratégia mais adequada. (SOUZA, 1998, p.67)

A avaliação formativa é contínua e visa a uma regulação interativa, ou seja, todas as relações entre professor e aluno são avaliações que possibilitam adaptações na prática cotidiana visando à melhor aprendizagem do aluno.

Conforme Bloom; Hastings e Madaus (1983),

na avaliação formativa é necessário “[...] tentar investigar os tipos de evidências mais úteis ao processo, procurar o melhor método de relatar essas evidências, e encontrar formas de reduzir os efeitos negativos associados à avaliação. ( Bloom; Hastings e Madaus 1983, p. 130)

Nesta perspectiva:

É uma avaliação que contribui para melhorar a aprendizagem, pois, informa ao professor sobre o desenvolver da aprendizagem e ao aluno sobre os seus sucessos e fracassos, o seu próprio caminhar. Assim, proporciona segurança e confiança do aluno nele próprio; feedback ao dar rapidamente informações úteis sobre etapas vencidas e dificuldades encontradas; diálogo entre professor e aluno, bem fundamentado em 
dados precisos e consistentes. Além disso, a avaliação formativa assume uma função reguladora, quando permite tanto a alunos como os professores ajustarem estratégias e dispositivos. Ela pode reforçar positivamente qualquer competência que esteja de acordo com alguns objetivos previamente estabelecidos e permitir ao próprio aluno analisar situações, reconhecer e corrigir seus eventuais erros nas tarefas. (RABELO,1998, p. 73 - 74)

A avaliação formativa indica o que deveria ser feito para tornar a avaliação verdadeiramente útil em situação pedagógica. Considera-se que a avaliação formativa é uma avaliação informativa (HADJI, 2001, p. 20).

Caracteriza-se por um processo interpretação - intervenção sobre o desenvolvimento do ensino-aprendizagem com a finalidade de garantilo, aprimorá-lo, direcioná-lo, enfim, de dar condições efetivas para que o ensino e a aprendizagem ocorram com sucesso. (SILVA, HOFFMANN, ESTEBAN, 2003, p. 39).

[...] para além de dar mais oportunidade ao aluno, permitindo-lhe repensar as questões colocadas, é talvez um contributo para que "eles tenham uma atitude diferente em relação à Matemática e possam adquirir mais confiança em si próprios” (LEAL, 1992, p. 255).

"É formativa toda a avaliação que auxilia o aluno a aprender e a se desenvolver, ou seja, que colabora para a regulação das aprendizagens e do desenvolvimento no sentido de um projeto educativo" (PERRENOUD apud HADJI, 2001, p. 20).

Para Méndez (2002, p. 82), a avaliação deve “[...] constituir uma oportunidade real de demonstrar o que os sujeitos sabem e como o sabem. Somente assim o professor poderá detectar a consistência do saber adquirido e a solidez sobre a qual vai construindo seu conhecimento".

Nesse aspecto:

A finalidade da avaliação, ao desencadear estudos, não é assim, a de simplesmente observar se os alunos apresentam ou não condições de "dar conta" das propostas delineadas, ou perceber, de início, os que apresentam mais ou menos dificuldades em determinada área. Mas a de conhecê-los cada vez melhor, tateando em busca de questões que verdadeiramente os provoquem a agir, à escuta de suas próprias questões, propondo em conjunto situações que lhes sejam verdadeiramente problemáticas a ponto de lhes despertar a atividade, a curiosidade [...] (HOFFMANN, 1995, p. 86) 
Segundo Haydt (1988), quando se avalia uma classe, durante ou no final de uma unidade de ensino, e a maioria dos alunos não atingiram um bom resultado, o professor, antes de qualquer coisa, deve questionar a eficácia do seu trabalho didático, ele mesmo deve se avaliar. Ele deve se perguntar se sua linguagem está adequada, se os alunos compreendem o que ele fala, se precisa mudar sua maneira de ensinar, utilizando procedimentos mais eficazes para a fixação dos conteúdos trabalhados, propor situações que motivem seus alunos, entre outros.

Dessa forma:

Essas perguntas e outras mais o professor pode fazer a si mesmo, na tentativa de repensar o seu trabalho em sala de aula. Cabe a ele replanejar a sua atuação didática, verificando de que forma pode aperfeiçoá-la, para que seus alunos obtenham mais êxito na aprendizagem. [...] É se colocando essas e outras questões que o professor poderá encontrar novos caminhos na tentativa de melhorar o processo ensino-aprendizagem dos alunos de baixo aproveitamento. (HAYDT, 1988, p. 22)

Na visão de Bloom; Hastings e Madaus (1983, p. 142), “[...] a nosso ver, o maior mérito da avaliação formativa está na ajuda que ela pode dar ao aluno em relação à aprendizagem da matéria e dos comportamentos, em cada unidade de aprendizagem”. Deste modo:

[...] a avaliação formativa não apenas fornece dados para que o professor possa realizar um trabalho de recuperação e aperfeiçoar seus procedimentos de ensino como também oferece ao aluno informação sobre seu desempenho em decorrência da aprendizagem, fazendo-o conhecer seus erros e acertos e dando-lhe oportunidade para recuperar suas deficiências. É nesse sentido que a avaliação assume sua dimensão orientadora, criando condições para a recuperação paralela e orientando o estudo contínuo e sistemático do aluno, para que sua aprendizagem possa avançar em direção aos objetivos propostos. (HAYDT, 1988, p 21)

Ainda nesta mesma linha de considerações, acrescentam que “[...] se um estudante não aprende, não é apenas porque não estuda ou não possui as capacidades mínimas: a causa pode estar nas atividades que lhe são propostas”. (JORBA; SANMARTÍ, 2003, p. 30).

Segundo Jorba e Sanmartí (2003), a avaliação formativa “[...] responde a uma concepção do ensino que considera que aprender é um longo processo por meio do qual o aluno vai reestruturando seu conhecimento a partir das atividades que executa”. 
Nesta perspectiva:

Esse tipo de avaliação tem, pois, como finalidade fundamental, uma função ajustadora do processo de ensino - aprendizagem para possibilitar que os meios de formação respondam às características dos estudantes. Pretende, principalmente, detectar os pontos frágeis da aprendizagem, mais do que determinar quais os resultados obtidos com essa aprendizagem. [...] os erros são objetos de estudo, pois revelam a natureza das representações ou estratégias elaboradas pelo estudante. Por meio dos erros, pode-se diagnosticar que tipo de dificuldades têm os estudantes para realizar as tarefas propostas e dessa maneira poder arbitrar os mecanismos necessários para ajudá-los a superarem-nas. (JORBA; SANMARTÍ, 2003, p. 30)

É necessário que a avaliação seja um momento prazeroso, onde os alunos se sintam à vontade neste elo do processo de ensino - aprendizagem, com recursos eficientes que possibilite a atenção para a aquisição da construção do conhecimento e não um momento de acerto de contas, de exclusão, de julgamento e de medição.

Dessa forma, Luckesi (2000) enfatiza:

[...] Chega de confundir a avaliação da aprendizagem com exames. A avaliação da aprendizagem, por ser avaliação, é amorosa, inclusiva, dinâmica e construtiva, diversa dos exames, que não são amorosos, são excludentes, não são construtivos, mas classificatórios. A avaliação inclui, traz para dentro; os exames selecionam, excluem, marginalizam. (LUCKESI, 2000, p. 07)

Portanto qual a importância de realizar a avaliação formativa? De acordo com Mezzaroba; Alvarenga (1999, p. 67), “[...] porque visa melhorar a formação do aluno; sua preocupação maior é ajudar o aluno a aprender e o mestre a ensinar. Por isso, deve ocorrer desde o início do ano escolar, em todas as matérias [...]".

\subsection{Avaliação Somativa}

A avaliação somativa tem aspecto autoritário e conservador e não funciona como um instrumento dialético do avanço, de novos rumos. Não serve em nada para a transformação, contudo, é extremamente eficiente para a conservação da estrutura social, pois exacerba a autoridade e oprime o educando, impedindo o seu crescimento. 
O arbítrio do professor aqui é total. Ele decide, sem critério prévio e sem relevância dos dados, conceder ou retirar pontos. Nesse caso, a competência é desconsiderada. Vale a gana autoritária do professor que, com isso, pode aprovar incompetentes, agradar os queridos e reprimir e sujeitar os inquietos e malqueridos. A avaliação aqui ganha os foros do direito de premiar ou castigar dentro do ritual pedagógico.

Nesse aspecto, a avaliação somativa:

supõe uma comparação, pois o aluno é classificado segundo o nível de aproveitamento e rendimento alcançado, geralmente em comparação com os demais colegas, isto é, com o grupo classe. A ênfase no aspecto comparativo é própria da escola tradicional. É com esse propósito que é utilizada a avalição somativa, com função classificatória, pois ela consiste em classificar os resultados da aprendizagem alcançados pelos alunos ao final de um semestre, ano ou curso, de acordo com os níveis de aproveitamento preestabelecidos. Portanto, consiste em atribuir ao aluno uma nota ou conceito final para fins de promoção. (HAYDT, 1991 , p. 25, 26)

A avaliação, nessa perspectiva torna-se uma dicotomia entre educação e avaliação. São necessárias a tomada de consciência e a reflexão a respeito desta compreensão equivocada da avaliação com julgamento de resultados porque ela veio se transformando numa perigosa prática educativa.

A verdadeira função da avaliação no sistema de ensino está expressa na citação de Soares (1981), a seguir:

É um dos mais eficazes instrumentos de controle da oferta e do aproveitamento de oportunidades educacionais e sociais e de disseminação de um processo de seleção em que, sob uma aparente neutralidade e equidade a alguns são oferecidas sucessivas oportunidades educacionais e, em consequência, oportunidades sociais, enquanto a outras essas oportunidades são negadas, processo que se desenvolve segundo critérios que transcendem os fins declarados de avaliação. Segundo esses fins declarados, a avaliação educacional pretende verificar se o estudante alcançou, e em que grau, os objetivos que se propõe o processo de ensino. Implica e mascaradamente o controle das hierarquias sociais. (SOARES ,1981 p.47)

Esta avaliação é utilizada como uma forma de controle, no final do ano ou do curso, para avaliar quantos conteúdos os alunos aprenderam no geral. Esse tipo de avaliação é 
semelhante à avaliação comparativa, mas abrange tudo o que os alunos aprenderam ao longo do ano.

Uma vez que as avaliações somativas abrangem uma ampla variedade de conceitos de um determinado nível, elas não são capazes de avaliar nenhum conceito de maneira profunda.

Conforme Bloom; Hastings e Madaus (1983, p. 98), a avaliação somativa é realizada no final de um período de ensino, "[...] a fim de atribuir uma nota ou dar um certificado aos alunos, relativos a uma unidade, capítulo, curso ou trabalho semestral, entre outras coisas". E acrescentam que "[...] é justamente a avaliação que gera tanta ansiedade e defesa entre os alunos, professores e programadores do ensino". (BLOOM; HASTINGS; MADAUS, 1983, p. 128)

Nesta perspectiva:

A avaliação somativa, com função classificatória, realiza-se ao final de um curso, período letivo ou unidade de ensino, e consiste em classificar os alunos de acordo com níveis de aproveitamento previamente estabelecidos, geralmente tendo em vista sua promoção de uma série para outra, ou de um grau para outro. (HAYDT, 1988, p.18)

A avaliação somativa acontece no final do processo de ensino. Serve para ver o que o aluno aprendeu depois de todo conteúdo trabalhado pelo professor. São atribuídas notas que serão divulgadas posteriormente.

Para Rabelo (1998),

uma avaliação somativa normalmente "[...] é uma avaliação pontual, já que, habitualmente, acontece no final de uma unidade de ensino, de um curso, um ciclo ou um bimestre, sempre tratando de determinar o grau de domínio de alguns objetivos previamente estabelecidos". Acrescentando que "[...] faz um inventário com o objetivo social de pôr à prova, de verificar. Portanto, além de informar, situa e classifica. Sua principal função é dar certificado, titular”. (RABELO, 1998, p. 72).

Estas avaliações são aplicadas para todos os alunos em sala de aula, para que todos tenham uma oportunidade igual de demonstrarem o que sabem. Os alunos demonstram sua capacidade de desempenho em um nível prescrito como padrão para o teste de proficiência.

Segundo Hoffmann (1993),

a avaliação tem se caracterizado como disciplinadora, punitiva e discriminatória, como decorrência, essencialmente, da ação corretiva 
do professor e os enunciados que emite a partir dessa correção. Daí a crítica que faço sobre a utilização de notas, conceitos, estrelinhas, carimbos, e outras menções nas tarefas dos alunos. O sentido discriminatório da avaliação começa nesse momento. As crianças comparam as tarefas entre si, o número de estrelinhas, os décimos e centésimos. Classificam-se, eles mesmos, em burros e inteligentes, e têm sua auto - estima abalada a ponto de surgirem bloqueios intransponíveis. (HOFFMANN, 1993, p. 111)

Para Luckesi (2002), os alunos têm sua atenção centrada na promoção. [...] O que predomina é a nota; não importa como elas foram obtidas nem por quais caminhos. São operadas e manipuladas como se nada tivessem a ver com o percurso ativo do processo de aprendizagem. [...] Os pais das crianças e dos jovens, em geral, estão na expectativa das notas dos seus filhos. O importante é que tenham notas para serem aprovados. (LUCKESI, 2002, p. 18-19).

Como nos mostra Rabelo (1998) “[...] o objetivo primeiro é uma boa aprendizagem. A avaliação deve tornar-se o momento e o meio de uma comunicação social clara e efetiva". (RABELO, 1998, p. 80).

Diante disso conclui que:

Não se pode confundir avaliação com nota e muito menos permitir que se continue usando o termo nota como sinônimo de avaliação. Nota é apenas uma forma dentre muitas de se expressar os resultados de uma avaliação. Não ter nota pode ser tão arbitrário e autoritário quanto tê-la. Precisamos apenas entender que a avaliação pode e deve alimentar, constantemente, o diálogo entre aluno e professor, permitindo a ambos, numa relação dialética, informações sobre fazeres e aprendizagens cada vez mais significativas para ambos. O professor precisa apoiar o aluno com informações que possam esclarecê-lo, encorajá-lo e orientá-lo quanto a possíveis sucessos e insucessos, permitindo-lhes situar melhor na sua jornada estudantil. (RABELO, 1998, p. 81)

Mediante o que vivenciamos é que a maioria dos professores se preocupa apenas no resultado dos alunos, se teve boa nota é considerado bom, se não obteve o mesmo sucesso é um mal caráter, um péssimo aluno, que com certeza será mais um entrega a sociedade para ser massacrado e julgado. 
CONCLUSÃO

O sistema de avaliação, apresenta-se como um novo jeito de caminhar e conduzir o processo avaliativo nas escolas da rede das escolas públicas, oportunizando aos professores e alunos um maior tempo de observação e construção do conhecimento. Espera - se que a avaliação produza resultados positivos, contribuindo de forma significativa para o sucesso de todos aqueles que lutam por uma educação de qualidade.

Cuja intuito no cotidiano possibilitar a aquisição de conhecimentos e de habilidades para a adaptação bem-sucedida em um mundo submetido a constantes transformações. Assim, para serem aprendizes efetivos por toda a vida, os jovens precisam de base sólida em domínios chave e devem ser capazes de organizar e gerir o aprendizado, o que requer consciência a respeito da própria capacidade de raciocínio e de estratégias e métodos de aprendizado.

Diante do que até aqui se expôs, a avaliação, bem como tudo o que nela se insere, é um direito social com prerrogativas legais, de modo que a formação de um aluno letrado, consciente de seus direitos e deveres, apto ao exercício da cidadania e consequente participação social é algo imprescindível nos dias atuais.

\section{REFERENNCIAS}

BLOOM, B.; HASTINGS, J. T.; MADAUS, G. F. Manual de avaliação formativa e somativa do aprendizado escolar. São Paulo: Pioneira, 1983

BRASIl, Secretaria de Educação Fundamental. Parâmetros Curriculares Nacionais: $3^{\circ}$ e $4^{\circ}$ ciclos do ensino fundamental/ SEF. - Brasília / MEC/ SEF, 1998.

CANEN, A. Avaliação da aprendizagem em sociedades multiculturais. Rio de Janeiro: Papel \& Virtual, 1999.

HADJI, Charles. A Avaliação desmitificada. Porto Alegre: Artmed, 2001.

HAYDT, R. C. C. Avaliação do processo ensino-aprendizagem. São Paulo: Ática, 1988.

HOFFMANN, J. Avaliação mediadora: uma prática em construção da pré-escola à universidade. 7. Ed. Porto Alegre: Mediação, 1993.

JORBA, J.; SANMARTÍ, N. A função pedagógica da avaliação. In: BALLESTER, M.et al. Avaliação como apoio à aprendizagem. Porto Alegre: Artmed, 2003.

KRAEMER, Maria Elisabeth Pereira. Avaliação da aprendizagem como construção do saber. 19/07/2006. 
LUCKESI, C.C.. Avaliação da aprendizagem na escola: reelaborando conceitos e recriando a prática. Salvador: Malabares Comunicação e Eventos, 2003.

LUCKESI, Cipriano Carlos. Avaliação da aprendizagem escolar. 14 ed. São Paulo: Cortez, 2002.

LUCKESI, Cipriano Carlos. Avaliação da Aprendizagem Escolar. 15 a ed. São Paulo: Cortez, 2003.

LUCKESI, Cipriano Carlos. Avaliação da aprendizagem escolar: estudos e proposições. $6^{\mathrm{a}}$ Edição, São Paulo, SP: Editora Cortez, 1997.

MACHADO, Maria Auxiliadora C. Araújo. Diagnóstico para superar o tabu da avaliação nas escolas. AMAE Educando, n. 255, 1995.

MÉNDEZ, Juan Manuel Àlvarez. Avaliar para Conhecer, Examinar para Excluir. Tradução Magda Schwartzhaupt Chaves. Porto Alegre: Artmed, 2002.

PERRENOUD, Philippe. Avaliação: da excelência à regulação das aprendizagens - entre duas lógicas. Porto Alegre: Artes Médicas Sul, 1999.

RABELO, E. H. Avaliação: novos tempos e novas práticas. Petrópolis, RJ: Vozes, 1998.

SANT'ANNA, I. M. Por que avaliar? Como avaliar?: critérios e instrumentos. 16. ed. Petrópolis, Rio de Janeiro: Vozes, 2013.

SANT'ANNA, Ilza Martins. Por que avaliar?: Como avaliar?: Critérios e instrumentos.3 ${ }^{\mathrm{a}}$ Edição, Petrópolis, RJ: Vozes, 1995

SOARES, Magda B. Avaliação educacional e clientela escolar: Introdução à psicologia escolar. São Paulo: T.A. Queiroz, 1981. p. 47-53.

SOUSA, S. M. Z. L. Avaliação escolar e democratização: o direito de errar. In: AQUINO, J. G. (Org.). Erro e fracasso na escola: alternativas teóricas e práticas. São Paulo: Summus, 1997. p.127.

SOUZA, S. Z. L. A prática avaliativa na escola de $1^{\circ}$ grau. In: SOUZA, C. P. de. (org.) Avaliação do rendimento escolar. Campinas, SP: Papirus, 1997. 